\title{
Variation of Stability Constants of Thorium and Uranium Oxalate Complexes with Ionic Strength
}

\author{
By H. N. Erten ${ }^{1}$, A. K. Mohammed ${ }^{2}$ and G. R. Choppin \\ Department of Chemistry, Florida State University, Tallahassee, Florida 32306-3006
}

\section{Thorium / Uranyl / Oxalate / Complexation / Solvent extraction}

\begin{abstract}
The extraction of Th(IV) and $\mathrm{UO}_{2}^{2+}$ by a solution of TTA and HDEHP, respectively in toluene has been used to obtain stability constants of their oxalate complexes at $298 \mathrm{~K}$ in 1, 3, 5, 7 and $9 \mathrm{M}$ ionic strength $\left(\mathrm{NaClO}_{4}\right)$ solutions. The complexes formed were the MOx, MHOx, MOx ${ }_{2}$ and $\mathrm{M}(\mathrm{HOx})_{2}\left(\mathrm{M}=\mathrm{Th}, \mathrm{UO}_{2}\right)$ species. The values were analyzed by the Specific Interaction Theory and agreed to $I \leq 3 \mathrm{M}$ but required an additional term for fitting at $I>3 \mathrm{M}$.
\end{abstract}

\section{Introduction}

The use of nuclear energy requires an ability to dispose safely of the resulting nuclear wastes. The solution chemistry of the actinides in connection with nuclear fuel reprocessing cycles as well as with their behavior in the environment associated with geological repositories is of major interest presently. The hydrolysis of actinide cations in natural waters can limit their solubility, lead to precipitation or sorption, and reduce complexation by other ligands in the waters. For modeling requirements, stability constant values are necessary for the ligands of interest in natural waters as well as hydrolysis constants. Normal titration techniques to determine such constants require relatively high metal ion concentrations which may be prevented by hydrolysis. Furthermore, such concentrations can lead to radiolysis which can complicate the measurements and perturb the results. These difficulties can be avoided by using solvent extraction techniques with tracer concentrations of the metal ions [1-4].

In this study, the stability constants of thorium and uranium oxalate complexes were measured over a range of ionic strengths.

The distribution coefficient, $D$, is defined for the extraction system as:

$$
D=\Sigma[\mathrm{M}]_{0} / \Sigma[\mathrm{M}]_{a} .
$$

Assuming only a single organic phase species, $\mathbf{M A}_{n}$, and the various species in the aqueous phase, equation (1) can be expressed by:

\footnotetext{
${ }^{1}$ On leave of absence from Bilkent University, 06533 Bilkent, Ankara, Turkey.

2 Present address: Department of Chemistry, North Carolina A and T State University, Greensboro, North Carolina 27411, USA.
}

$$
\begin{aligned}
D & =\left[\mathrm{MA}_{n}\right]_{0} /\left([\mathrm{M}]_{a}+[\mathrm{ML}]_{a}+[\mathrm{MHL}]_{a}\right. \\
& +\left[\mathrm{ML}_{2}\right]_{a}+\left[\mathrm{M}(\mathrm{HL})_{2}\right]_{a}+\ldots
\end{aligned}
$$

where $\mathrm{L}$ is a complexing anion in the aqueous phase. This equation can be written, with the conventional symbols for stability constants, [5] as,

$$
\begin{aligned}
D & =\left[\mathrm{MA}_{n}\right]_{0} /[\mathrm{M}]_{a}\left(1+\left(\beta_{101}+\beta_{111}[\mathrm{H}]\right)[\mathrm{L}]\right. \\
& \left.+\left(\beta_{102}+\beta_{122}[\mathrm{H}]^{2}\right)[\mathrm{L}]^{2}+\ldots\right)
\end{aligned}
$$

We define "apparent" stability constants as:

$$
\begin{aligned}
& \beta_{1}^{\text {app }} \equiv \beta_{101}+\beta_{111}[\mathrm{H}] \\
& \beta_{2}^{\text {app }} \equiv \beta_{102}+\beta_{122}[\mathrm{H}]^{2} .
\end{aligned}
$$

The constant in the absence of complexation is:

$$
D_{0} \equiv\left[\mathrm{MA}_{n}\right]_{0} /[\mathrm{M}]_{a} \text {. }
$$

This allows restating equation (3) as:

$$
D_{0} / D=1+\beta_{1}^{\text {app }}[\mathrm{L}]+\beta_{2}^{\text {app }}[\mathrm{L}]^{2}+\ldots
$$

A plot of $\beta_{1}^{\text {app }}$ vs. $[\mathrm{H}]$ should give a straight line with an intercept equal to $\beta_{101}$ and a slope of $\beta_{111}$ while a plot of $\beta_{2}^{\text {app }}$ vs. $[\mathrm{H}]^{2}$ should be linear with an intercept of $\beta_{102}$ and a slope of $\beta_{122}$.

\section{Experimental}

\section{Reagents and solutions}

All reagents were analytical grade. A stock solution of $0.0010 \mathrm{M}$ sodium oxalate (Aldrich) was prepared. Thenoyltrifluoroacetone, TTA, was purified by sublimation. A $0.01 \mathrm{M}$ stock solution of TTA in toluene was stored in the dark. Di-(2-ethylhexyl) phosphoric acid, HDEHP, (Pfaltz and Bauer Co.) was purified by precipitation as $\mathrm{Cu}(\mathrm{DEHP})_{2}$ using the procedure of McDowell et al. [6]. The purified HDEHP was dissolved in toluene and standardized with standard $\mathrm{NaOH}$ solution. Sodium perchlorate (anhydrous, Mallinckrodt) was used for ionic strength adjustment without further purification.

${ }^{230}$ Th tracer (from Oak Ridge National Laboratory) was prepared in a solution of $\mathrm{pH} 2\left(\mathrm{HClO}_{4}\right)$ such that $10 \mu \mathrm{l}$ contained ca. $4.5 \times 10^{4} \mathrm{cpm}$. ${ }^{233} \mathrm{U}$ tracer (Oak Ridge National Laboratory) was evaporated to dryness and dissolved in a $\mathrm{pH} 3\left(\mathrm{HClO}_{4}\right)$ solution such that $10 \mu \mathrm{l}$ of the solution had a count rate of $3.5 \times 10^{4} \mathrm{cpm}$. These count rates were obtained with the same efficiency as for the samples from the solvent extraction 
measurements. All solutions used in the experiments were filtered with a $0.45 \mu \mathrm{m}$ microfiltration system. Contamination from airborne particles was reduced by performing the experimental manipulations in a laminar flow hood (Environmental Air Control, Inc.).

\section{Silanizing}

To minimize the sorption of the uranyl and thorium radiotracers on extraction vials, the latter were silanized according to the process in reference [3]. The $20 \mathrm{ml}$ standard borosilicate scintillation vials were washed with $1 \mathrm{M} \mathrm{NaOH}$, soaked in $3 \mathrm{M} \mathrm{HCl}$, rinsed and dried at $100{ }^{\circ} \mathrm{C}$. The precleaned vials and their caps were silanized by shaking for 4-6 hours in a solution containing 5\% trimethylchlorosilane and 5\% hexamethyldisilazane in toluene. The vials were dried overnight at $120^{\circ} \mathrm{C}$.

\section{$\mathrm{pcH}$ Measurements}

A research pH meter (Accumet 950, Fischer Scientific) was used with a combination glass electrode. The $\mathrm{KCl}$ solution in the salt bridge was replaced with $\mathrm{NaCl}$ solution, as the low solubility of $\mathrm{KClO}_{4}$ at high ionic strengths causes erratic readings. The electrode was calibrated with $4.01 \pm 0.01$ and $7.00 \pm 0.01 \mathrm{pH}$ buffer standards. The $\mathrm{pH}$ readings were converted to hydrogen ion concentration $(\mathrm{pcH})$ using calibration curves obtained by a series of $\mathrm{HClO}_{4}$ dilutions in 1 to $9 \mathrm{M}$ $\mathrm{NaClO}_{4}$ solutions.

\section{Radioactive tracer}

The radioactive tracers used were checked for radioactive purity by alpha and gamma ray spectrometry. The alpha radioactivity in aliquots from the experiments was counted on a Packard Instrument Tri-Carb 4000 (Hewlett Packard Instruments) liquid scintillation counter using an emulsion scintillation cocktail (Ecolume, ICN Biomedicals Co.) for both aqueous and organic phases.

\section{Experimental procedure}

\section{Determination of the dissociation constants of oxalic acid}

The $\mathrm{p} K_{a}$ values of oxalic acid were determined at 3,5 , 7 , and $9 \mathrm{M}$ ionic strengths by potentiometric $\left(\mathrm{NaClO}_{4}\right)$ titration. The titrations were carried out using $40 \mathrm{ml}$ solutions in a $150 \mathrm{ml}$ vessel. A water bath maintained at $25 \pm 0.2^{\circ} \mathrm{C}$ was used for circulating water in the jacket of the titration vessel. The Gran method was used for calibrating the glass electrode at each ionic strength $[7,8]$. A standardized solution of $0.1 \mathrm{M}$ $\mathrm{HClO}_{4}$ (in $\mathrm{NaClO}_{4}$ of a certain ionic strength) was titrated against a volume $V_{0}$ of $\mathrm{NaClO}_{4}$ of the same ionic
Table 1. Dissociation constants of oxalic acid at different ionic strengths $\left(\mathrm{NaClO}_{4}\right)$ and $T=298 \mathrm{~K}$

\begin{tabular}{cll}
\hline $\mathrm{I}(\mathrm{M})$ & $\mathrm{p} K_{a 1}$ & $\mathrm{p} K_{a 2}$ \\
\hline 1 & $1.04 \pm 0.04[10]$ & $3.56 \pm 0.02[10]$ \\
3 & $1.3[10]$ & $3.81[10]$ \\
& $1.0 \pm 0.3($ p.w.) & $3.85 \pm 0.1$ (p.w.) \\
5 & $2.19 \pm 0.04$ & $4.47 \pm 0.01$ \\
7 & $2.61 \pm 0.04$ & $4.91 \pm 0.01$ \\
9 & $2.26 \pm 0.08$ & $5.20 \pm 0.01$ \\
\hline
\end{tabular}

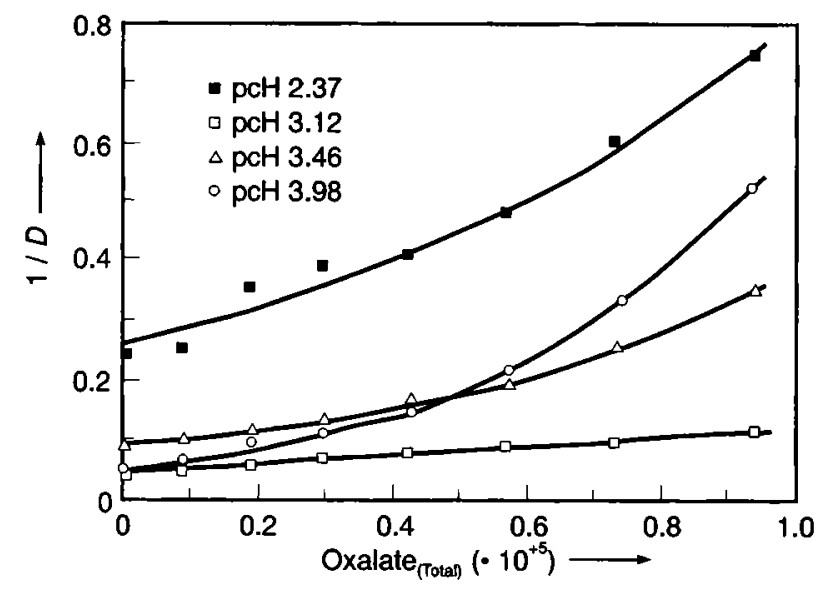

Fig. 1. The variation of $1 / D$ for Th(IV) as a function of total oxalate concentration at an ionic strength of $5 \mathrm{M} \mathrm{NaClO}_{4}$.

strength as that of $\mathrm{HClO}_{4}$. The exact concentration of the titrant $\left(\mathrm{HClO}_{4}\right.$ in $\left.\mathrm{NaClO}_{4}\right)$ was determined by titrating a known amount of $\mathrm{Na}_{2} \mathrm{CO}_{3}$ using bromocresol green as indicator. The titration used constant amounts of titrant for each addition. The data analysis of $\mathrm{p} K_{a}$ determination was done by using the Fortran program HNFITMQ [9].

\section{Solvent extraction procedure}

For each extraction experiment, $5.0 \mathrm{ml}$ of pre-equilibrated aqueous solution adjusted to the appropriate $\mathrm{pH}$ were placed in silanized vials. Aliquots of oxalate stock solution were added to each vial followed by $5 \mathrm{ml}$ of TTA and HEDHP in toluene. The concentration of the organic extractant was adjusted according to the ionic strength and $\mathrm{pH}$ of the solutions used. After addition of $10 \mu \mathrm{l}$ of either ${ }^{230} \mathrm{Th}$ or ${ }^{233} \mathrm{U}$, the vials were shaken for $2-3$ hours at room temperature. Kinetic measurements indicated that equilibrium was attained in these experiments in about $10 \mathrm{~min}(\mathrm{Th})$ and $1 \mathrm{~h} \mathrm{(U).} \mathrm{The} \mathrm{vials} \mathrm{were} \mathrm{centrifuged} \mathrm{and} \mathrm{duplicate} \mathrm{ali-}$ quots from both phases were taken for counting and pH measurement.

\section{Results}

\section{Dissociation constants of oxalic acid}

The experimental acid dissociation constants of oxalic acid are given in Table $1 . \mathrm{p} K_{a}$ values up to $3 \mathrm{M}$ ionic 
Table 2. Apparent stability constants of $\mathrm{Th}+\mathrm{Ox}$ complexes $(T=298 \mathrm{~K}) \cdot \log \beta_{1}^{\text {app }}$

\begin{tabular}{|c|c|c|c|c|c|}
\hline \multirow{2}{*}{$\mathrm{pcH}$} & \multicolumn{5}{|c|}{ Ionic strength } \\
\hline & $1 \mathrm{M}$ & $3 \mathrm{M}$ & $5 \mathrm{M}$ & $7 \mathrm{M}$ & $9 \mathrm{M}$ \\
\hline 1.29 & $7.92 \pm 0.06$ & $8.02 \pm 0.04$ & $8.96 \pm 0.02$ & $9.57 \pm 0.02$ & $8.92 \pm 0.02$ \\
\hline 1.40 & $7.90 \pm 0.01$ & $7.99 \pm 0.01$ & & & \\
\hline 1.50 & $7.88 \pm 0.02$ & & $8.68 \pm 0.02$ & & \\
\hline 1.58 & & $7.94 \pm 0.03$ & $8.66 \pm 0.05$ & & \\
\hline 1.67 & $7.79 \pm 0.05$ & & & & \\
\hline 1.84 & $7.70 \pm 0.02$ & $7.78 \pm 0.04$ & $8.37 \pm 0.06$ & $8.99 \pm 0.05$ & $8.79 \pm 0.07$ \\
\hline 1.90 & $7.62 \pm 0.03$ & & & & \\
\hline 1.94 & $7.58 \pm 0.04$ & & & & \\
\hline 2.17 & $7.37 \pm 0.01$ & & & & \\
\hline 2.30 & $7.44 \pm 0.06$ & & & & \\
\hline 2.37 & $7.19 \pm 0.04$ & & $7.68 \pm 0.07$ & $8.40 \pm 0.07$ & $8.53 \pm 0.04$ \\
\hline 2.41 & & $7.31 \pm 0.04$ & & & \\
\hline 3.08 & & & & $7.23 \pm 0.09$ & $7.27 \pm 0.04$ \\
\hline 3.12 & $6.76 \pm 0.02$ & $6.78 \pm 0.05$ & $6.76 \pm 0.04$ & & $7.18 \pm 0.04$ \\
\hline 3.32 & & & & $7.15 \pm 0.05$ & $7.08 \pm 0.01$ \\
\hline 3.46 & $6.50 \pm 0.04$ & $6.47 \pm 0.01$ & $6.45 \pm 0.01$ & $6.91 \pm 0.05$ & $7.14 \pm 0.05$ \\
\hline 3.98 & $6.00 \pm 0.08$ & $6.09 \pm 0.17$ & $6.29 \pm 0.07$ & $6.75 \pm 0.08$ & $7.06 \pm 0.10$ \\
\hline
\end{tabular}

Table 3. Apparent stability constants of $\mathrm{Th}+\mathrm{Ox}$ complexes $(T=298 \mathrm{~K}) \cdot \log \beta_{2}^{\text {app }}$

\begin{tabular}{|c|c|c|c|c|c|}
\hline \multirow{2}{*}{$\mathrm{pcH}$} & \multicolumn{5}{|c|}{ Ionic strength } \\
\hline & $1 \mathrm{M}$ & $3 \mathrm{M}$ & $5 \mathrm{M}$ & $7 \mathrm{M}$ & $9 \mathrm{M}$ \\
\hline 1.29 & $13.34 \pm 0.31$ & $14.26 \pm 0.34$ & $16.31 \pm 0.45$ & $18.16 \pm 0.17$ & $17.49 \pm 0.14$ \\
\hline 1.40 & $13.62 \pm 0.14$ & $13.94 \pm 0.35$ & & & \\
\hline 1.50 & $13.62 \pm 0.13$ & & & & \\
\hline 1.67 & $13.78 \pm 0.02$ & & & & \\
\hline 1.84 & $13.71 \pm 0.01$ & $13.66 \pm 0.16$ & $15.90 \pm 0.02$ & $16.81 \pm 0.42$ & $16.23 \pm 0.76$ \\
\hline 1.90 & $13.61 \pm 0.05$ & & & & \\
\hline 2.17 & $13.44 \pm 0.03$ & & & & \\
\hline 2.37 & $13.00 \pm 0.02$ & & & & $15.98 \pm 0.03$ \\
\hline 3.12 & $12.79 \pm 0.03$ & $12.76 \pm 0.07$ & $12.44 \pm 0.04$ & $13.63 \pm 0.03$ & $14.31 \pm 0.03$ \\
\hline 3.46 & $12.16 \pm 0.02$ & $12.18 \pm 0.03$ & $12.47 \pm 0.02$ & $13.30 \pm 0.05$ & $13.13 \pm 0.31$ \\
\hline 3.98 & $12.99 \pm 0.04$ & $12.06 \pm 0.02$ & $12.23 \pm 0.05$ & $13.77 \pm 0.02$ & $13.17 \pm 0.14$ \\
\hline
\end{tabular}

strength are reported in the literature [10]. The $\mathrm{p} K_{a 1}$ values have somewhat larger errors than those of $\mathrm{p} K_{a 2}$, reflecting the increased difficulty in determining the values for $\mathrm{p} K_{a 1}$.

\section{The thorium oxalate complexes}

Speciation calculations of the oxalate ligand indicate that in the $\mathrm{pcH}$ range of these studies the predominant species is the protonated anion $\mathrm{HOx}^{-}$.

\section{Metal oxalate complexation}

A series of experiments covering $\mathrm{pH}$ 's from 1.3 to 4.0 were conducted at ionic strengths of $1,3,5,7$, and $9 \mathrm{M} \mathrm{NaClO}_{4}$. The concentration of oxalate anion in each vial was calculated from the measured $\mathrm{pcH}$, the total oxalate and the $\mathrm{p} K_{a}$ values of oxalic acid.

Typical curves showing the variation of $1 / D$ with oxalate anion concentration at different $\mathrm{pcH}$ values are shown in Figure 1. The data were analyzed with Eq. (7) when nonlinear curves were obtained over higher oxalate ranges as this indicates the presence of both $1: 1$ and $1: 2$ complexes. From analysis of the curves, the apparent stability constants $\beta_{1}^{\text {app }}$ and $\beta_{2}^{\text {app }}$ were obtained as listed in Tables 2,3 , and 4 . These values represent results of at least two determinations. The relationship of these apparent stability constants to the $\beta_{101}, \beta_{111}, \beta_{102}$, and $\beta_{122}$ stability constants are given by Equations (4) and (5). Figure 2 is a plot of the apparent $\beta_{1}^{\text {app }}$ as a function of hydrogen ion concentration. The intercept and slope of the linear least squares fit correspond to $\beta_{101}$ and $\beta_{111}$, respectively. This technique where by the perturbation of complexing by oxalate due to competitive hydrolysis can be used only where hydrolysis has not proceeded too far. The deviation from linearity at low $\left[\mathrm{H}^{+}\right]$in Figure 2 reflects this problem which is also observed by a poor mass balance due to sorption and/or precipitation of the neutral hydroxide. The slope at higher $\left[\mathrm{H}^{+}\right]$values becomes unreliable due to small degree of complexation 
Table 4. Apparent stability constants of the $\mathrm{UO}_{2}^{2+}+$ Ox complexes $(T=298 \mathrm{~K}) \cdot \log \beta_{1}^{\text {app }}$ and $\log \beta_{2}^{\text {app }}$

\begin{tabular}{|c|c|c|c|c|}
\hline \multirow{2}{*}{$\mathrm{pcH}$} & \multicolumn{4}{|c|}{ Ionic strength } \\
\hline & $3 \mathbf{M}$ & $5 \mathrm{M}$ & $7 \mathrm{M}$ & $9 \mathrm{M}$ \\
\hline 1.61 & $6.20 \pm 0.02$ & & & \\
\hline 1.89 & $6.13 \pm 0.01$ & & & \\
\hline 2.19 & $6.07 \pm 0.02$ & & & \\
\hline 2.23 & & & & $7.96 \pm 0.03$ \\
\hline 2.27 & & $7.16 \pm 0.02$ & & \\
\hline 2.32 & $6.12 \pm 0.02$ & & & \\
\hline 2.49 & & $6.70 \pm 0.02$ & & \\
\hline 2.79 & & $6.80 \pm 0.05$ & & \\
\hline 2.84 & & & $7.60 \pm 0.06$ & \\
\hline 3.03 & & $\begin{array}{c}6.92 \pm 0.01 \\
(12.92 \pm 0.01)\end{array}$ & & \\
\hline 3.07 & & & $\begin{array}{c}7.50 \pm 0.05 \\
(14.43 \pm 0.21)\end{array}$ & \\
\hline 3.11 & & & & $\begin{array}{c}7.54 \pm 0.04 \\
(14.14 \pm 0.09)\end{array}$ \\
\hline 3.22 & $\begin{array}{c}6.05 \pm 0.06 \\
(11.07 \pm 0.20)\end{array}$ & & & \\
\hline 3.34 & & & & $\begin{array}{c}7.43 \pm 0.04 \\
(14.09 \pm 0.10)\end{array}$ \\
\hline 3.42 & $\begin{array}{c}5.97 \pm 0.06 \\
(11.09 \pm 0.10)\end{array}$ & & & \\
\hline 3.52 & & $\begin{array}{c}6.84 \pm 0.04 \\
(12.40 \pm 0.11)\end{array}$ & & \\
\hline 3.54 & & & $\begin{array}{c}7.04 \pm 0.06 \\
(13.18 \pm 0.19)\end{array}$ & \\
\hline
\end{tabular}

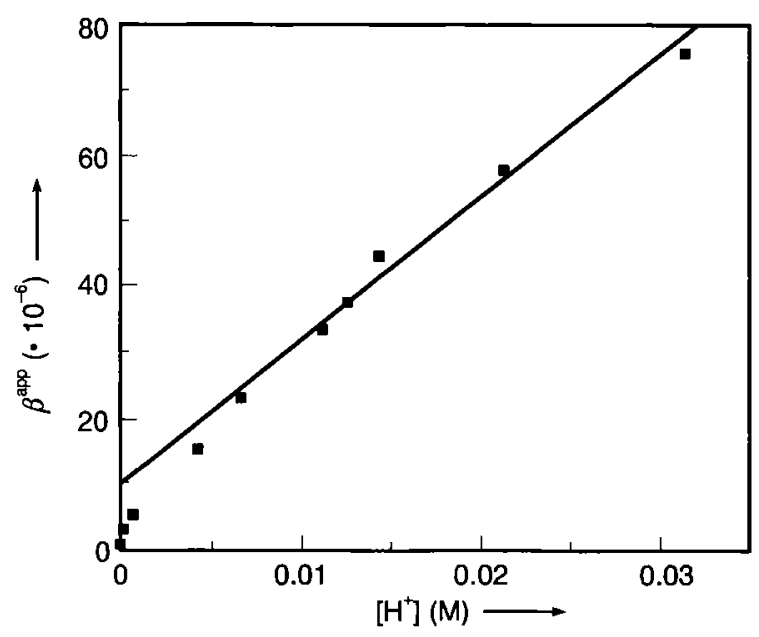

Fig. 2. Variation of the apparent stability constant, $\beta_{1}^{\text {app }}$, for thorium plus oxalate complexes as a function of hydrogen ion concentration at $1 \mathrm{M}$ ionic strength.

and the values at $\mathrm{pcH} 1.29$ and 1.40 have not been included in Figure 2 . The $\beta_{101}, \beta_{102}, \beta_{111}$, and $\beta_{122}$ values are given in Tables 5 (a) and (b) where the errors indicated represent $1 \sigma$.

\section{Discussion}

The bonding of Th(IV) to inorganic and organic ligands in complexes can be described by an ionic model. As a result the number of ligands as well as their geometric arrangement about the thorium cation are determined primarily by electrostatic and steric factors. The hydrolysis of Th(IV) can be extensive even in relatively acidic solutions $(\mathrm{pH} \geq 1)$. Since most organic ligands involving carboxylate groups (e.g., oxalate) require $\mathrm{pH}$ values of 3 or higher in order to provide enough ionization of the ligand for interaction, studies of thorium complexation are limited due to hydrolytic competition. Only a single study exists in the literature of the stability constants $\beta_{101}$ and $\beta_{102}$ of thorium-oxalate complexes in perchlorate solution [11] obtained from solubility measurements. Our values are not in agreement with these data.

Uranyl ion, $\mathrm{UO}_{2}^{2+}$, does not hydrolyze as readily and has been studied more extensively than thorium. Stability constants for the $\mathrm{UO}_{2}^{2+}$-oxalate system are available in the literature for $4 \mathrm{M}$ ionic strength [11, $12,13]$ and below. In the present work, we obtained a $\log \beta_{101}$ of $6.00 \pm 0.05$ which compares well with that reported at $4 \mathrm{M}[13]$.

The Nuclear Energy Agency has recommended [14] the use of Specific Ion Interaction Theory (SIT) in the analysis of stability constants measured at different ionic strengths up to ca. $3 \mathrm{~m}$. In the SIT approach, the value of the stability constant at zero ionic strength, $\beta^{o}$, is related to the value $\beta^{1}$ at ionic strength I (in molality) by:

$$
\log \beta^{\mathrm{I}}=\log \beta^{0} \pm \Delta Z^{2} \cdot D-\Delta \varepsilon \cdot I .
$$

Here,

$$
\Delta Z^{2}=\left(Z_{\mathrm{ML}}\right)^{2}-Z_{\mathrm{M}}^{2}-Z_{\mathrm{L}}^{2}
$$

and 
Table 5. (a) Stability constants of Th + Ox complexes

\begin{tabular}{ccccc}
\hline$I(\mathrm{M})$ & $\log \beta_{101}$ & $\log \beta_{111}$ & $\log \beta_{102}$ & $\log \beta_{122}$ \\
\hline 1 & $6.93 \pm 0.03$ & $9.47 \pm 0.01$ & $13.13 \pm 0.17$ & $17.01 \pm 0.04$ \\
3 & $7.06 \pm 0.09$ & $9.52 \pm 0.12$ & $13.16 \pm 0.05$ & $16.95 \pm 0.03$ \\
5 & $7.12 \pm 0.08$ & $10.24 \pm 0.05$ & $13.19 \pm 0.17$ & $19.29 \pm 0.01$ \\
7 & $7.37 \pm 0.04$ & $10.84 \pm 0.01$ & $13.76 \pm 0.06$ & $20.21 \pm 0.01$ \\
9 & $6.74 \pm 0.12$ & $10.63 \pm 0.01$ & $13.03 \pm 0.18$ & $19.79 \pm 0.01$ \\
\hline
\end{tabular}

(b) Stability constants of $\mathrm{UO}_{2}^{2+}+\mathrm{Ox}$ complexes

\begin{tabular}{ccrcc}
\hline$I(\mathrm{M})$ & $\log \beta_{101}$ & $\log \beta_{111}$ & $\log \beta_{102}$ & $\log \beta_{122}$ \\
\hline 1 & $5.99^{11}$ & & & \\
3 & $6.00 \pm 0.05$ & $7.57 \pm 0.06$ & $11.21 \pm 0.18$ & $18.86 \pm 0.15$ \\
5 & $6.55 \pm 0.28$ & $9.22 \pm 0.17$ & $12.28 \pm 0.11$ & $12.94 \pm 0.40$ \\
7 & $6.55 \pm 0.33$ & $10.43 \pm 0.07$ & $14.08 \pm 0.11$ & $19.48 \pm 0.59$ \\
9 & $7.37 \pm 0.05$ & $10.06 \pm 0.02$ & \\
\hline
\end{tabular}

Table 6. Results of the extended SIT analysis

\begin{tabular}{lccc}
\hline Species & $\log \beta^{\circ}$ & $\Delta \varepsilon$ & $\Delta \delta$ \\
\hline $\mathrm{HOx}^{-}$ & 4.33 & 0.26 & -0.0062 \\
$\mathrm{UO}_{2} \mathrm{HOx}^{+}$ & 5.60 & 1.03 & -0.044 \\
$\mathrm{UO}_{2} \mathrm{Ox}$ & 5.60 & 0.45 & -0.019 \\
$\mathrm{ThHOx}^{3+}$ & 11.0 & 0.51 & -0.020 \\
$\mathrm{ThOx}^{2+}$ & 9.8 & 0.42 & -0.022 \\
Th(HOx ${ }^{2+}$ & 18.13 & 1.42 & -0.061 \\
ThOx $_{2}$ & 17.5 & 0.56 & -0.028 \\
\hline
\end{tabular}

$$
\begin{aligned}
& D=0.509 \mathrm{I}^{1 / 2} / 1+1.5 \mathrm{I}^{1 / 2} \\
& \Delta \varepsilon=\varepsilon_{\mathrm{ML}}-\varepsilon_{\mathrm{M}}-\varepsilon_{\mathrm{L}}
\end{aligned}
$$

where $Z$ is the charge on the designated species and $\varepsilon$ is an interaction coefficient for the cation and anion pair. Values of $\log \beta$ predicted by the SIT agree well with the experimental values from 0 to ca. $3 \mathrm{M}$ ionic strength. Above $\mathrm{I}=3 \mathrm{M}$ there is usually a growing difference between the experimental data and the SIT calculation.

Recently an extension of the SIT treatment has been proposed [15] to cover higher ionic strengths by including a quadratic term of the interaction, $+\Delta \delta \cdot \mathrm{I}^{2}$, in Equation (8). The results of extended SIT analysis of our data are given in Table 6 which Figure 3 illustrates the extended SIT fitting of the $\mathrm{ThOx}^{2+}$ complex stability constant. This extension of the S.I.T. treatment to higher ionic strengths is empirical and, generally, analyses at such ionic strengths have used the Pitzer formalism [16]. We have not used this latter approach in this study due to insufficient data to obtain the Pitzer parameters.

\section{Acknowledgments}

This research, carried out through the Waste Isolation Pilot Plant Project, was supported by the USDOE under Contract DE-1C04-76DP0089, and by Sandia

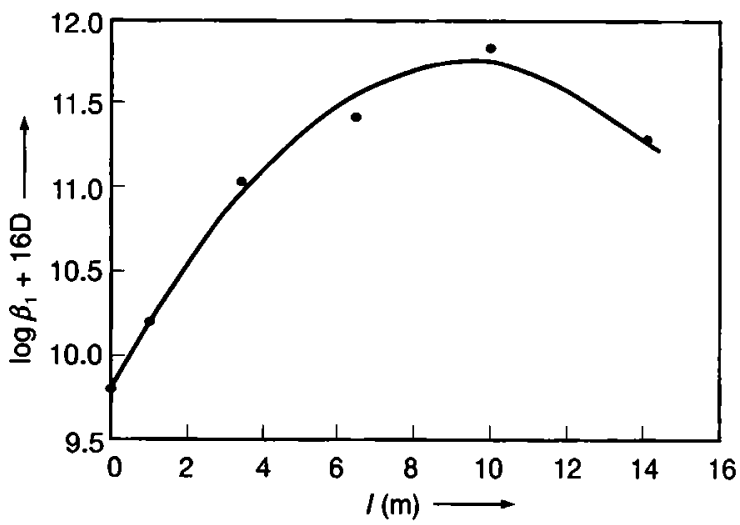

Fig. 3. The "extended" SIT treatment of the $\beta_{101}$ values for Th $+\mathrm{Ox}$ as a function of the ionic strength (in molality).

National Laboratories under Subcontract 691734 to Florida State University.

H.N. Erten acknowledges financial support from the Turkish Scientific and Technical Research Council (TUBITAK).

\section{References}

1. Khalili, F. I., Choppin, G. R., Rizkalla, E. N.: Inorg. Chim. Acta 143, 131 (1988).

2. Caceci, M. S., Choppin, G. R.: Radiochim. Acta 33, 101 (1983).

3. Caceci, M. S., Choppin, G. R.: Radiochim. Acta 33, 207 (1983).

4. Choppin, G. R., Mathur, J. N.: Radiochim. Acta 52/53 (1991).

5. Sillen, L. G., Martell, A. E.: Spec. Pub. Chem. Soc. No 17 (1964).

6. McDowell, W. J., Perdue, P. T., Case, G. N.: J. Inorg. Nucl. Chem. 328, 2127-2129 (1976).

7. Gran, G.: Acta Chem. Scand. 4, 559-577 (1950).

8. Gran, G.: Analyst 77, 661-671 (1952).

9. Torres, R. A.: Private communication, Lawrence Livermore National Laboratory (1990). 
10. Martell, A. E., Smith, R. M.: In Critical Stability Constants, Plenum: New York (1989), Vol. 6 (Second Supplement), p. 325.

11. Moskvin, A. I., Essen, L. N., Russian J. Inorg. Chem. 12, 630 (1967).

12. Miyake, C., Nurnberg, H. W.: J. Inorg. Nucl. Chem. 29, 2411-2429 (1967)

13. Havel, J.: Coll. Czech. Chem. Commun. 34, 3248-3265 (1969)
14. Grenthe, I., Fuger, J., Lemire, R., Muller, A., NguyenTrung, C., Wanner, H.: Chemical Thermodynamics of Uranium, NEA-TDB, OECD, France (1991).

15. Du, M.: Chemistry Department, Florida State University Tallahassee, Private Communication (1993).

16. Acitivity Coefficients in Electrolyte Solutions, 2nd Edition. Pitzer, K. S., Editor, CRC Press: Boca Raton, Florida, USA (1991). 